\title{
INTERVAL TYPE-2 FUZZY LOGIC CONTROL FOR THE MULTIVARIABLE ANAESTHESIA SYSTEM
}

\author{
Mohammad El-Bardini; Ahmad M. El-Nagar* and \\ Nabila M. El-Rabaie \\ Faculty of Electronic Engineering, Menouf, 32852, Egypt \\ *Eng.amn85@gmail.com
}

(Received July 3, 2010 Accepted September 15, 2010)

\begin{abstract}
Interval type-2 fuzzy sets are able to model and minimize the numerical and linguistic uncertainties associated with the inputs and outputs of the fuzzy logic controller (FLC). The main objective of this paper is to implement an interval type-2 FLC for controlling the multivariable anaesthesia system to overcome the uncertainty problem that introduced by large inter-individual and intraindividual variability of the patient's parameters. Simulation results show good performance over a wide range of inter and intraindividual variability of parameters. Also these show good performance under the effect of disturbance and noise environment. Results also show the interval type-2 FLC affords some improvements in performance over type-1 FLC.
\end{abstract}

KEY WORDS: Anaesthesia system, Interval Type-2 fuzzy sets, Interval type-2 FLC

\section{INTRODUCTION}

Anaesthesia is generally described as that part of the medical profession which ensures that the patient's body remains insensitive to pain and other stimuli during surgical operations. It includes muscle relaxation (paralysis), unconsciousness (hypnosis), and analgesia (pain relief) [1]. Muscle relaxation is induced to facilitate access to internal organs and to depress movement responses to surgical stimulation. The measurement of muscle relaxation is considerably easier than hypnosis and analgesia. Hypnosis is a general term indicating unconsciousness and absence of postoperative recall of events that occurred during surgery. Analgesia is associated with pain relief but at present, there are no specific measures to quantify it, as it is even debatable to speak about pain perception when the patient is unconscious [2].

In practice, the anaesthetist has a number of clinical signs and on-line measurements which can be used selectively for the determination of the patient's state such as blood pressure, heart rate, and electroencephalography (EEG) pattern $[2,3]$. The aim of an anaesthesia control system is the automatisation of some control tasks of the anaesthetist in normal situation to avoid dangerous situations, the anaesthetist should always have a clear overview of the state of the automated processes [4]. Two drugs, atracurium and isoflurane, are commonly used for general anaesthesia. These drugs interact the anaesthesia and muscle 
relaxation signs that are the mean arterial blood pressure (MABP) and the evoked electromyogram (EMG) respectively [5].

There are two main problems in multivariable anaesthesia system. First, the nonlinear structure in the so-called pharmacodynamics for the relaxant drugs behaviour may be make the muscle relaxation level to saturate with any large control dose. Second, there is a great uncertainty inherited from the large interindividual and intra-individual variability of the patient's parameters and the large delay time of this process. Hence, these problems make the multivariable anaesthesia system is a very challenging one. The generalized predictive control (GPC) algorithm and the self-organized fuzzy logic control (SOFLC) have been proposed to deal with the multivariable anaesthesia problem [3]. A novel neural network-based control scheme has been also proposed to deal with such problem [6]. Type-1 FLC has been also proposed to deal with the anaesthesia system $[4,7,8,9]$.

The concept of type- 2 fuzzy sets is an extension of the concept of the ordinary fuzzy sets (type-1 fuzzy sets). A type-2 fuzzy set is characterized by a fuzzy membership function, i.e., the membership grade for each element of this set is a fuzzy set in $[0,1]$, unlike type-1 fuzzy set where the membership grade is a crisp number in $[0,1][10]$. Therefore, type- 2 fuzzy set provides additional degrees of freedom that can make it possible to directly model and handle the uncertainties [11]. The interval type-2 fuzzy logic control (IT2-FLC) is a special case of the type-2 fuzzy logic system [12]. IT2-FLCs have been applied to various fields with great success $[5,10,12,13,14,15,16]$.

There are several types of modeling for anaesthesia system where these types differ from other on the type of drug used and the number of the controlled variables. The aim of this paper is to apply IT2-FLC to the multivariable anaesthesia system that described in section 2 to overcome the uncertainty problem, the disturbance of the controlled variables and noise environment. Also, we are applying T1-FLC as another technique to the same anaesthesia model to compare the results with the ones of IT2-FLC to test the robustness of the IT2FLC to deal with multivariable anaesthesia system.

This paper can be organized as follows. The description of the mathematical model of the multivariable anaesthesia system is presented in section 2 . Section 3 provides a brief overview of type- 2 fuzzy logic systems. In section 4, we present the IT2-FLC for multivariable anaesthesia system. The simulation results are given in section 5. Section 6 concludes the topics discussed in this paper.

\section{MULTIVARIABLE ANAESTHESIA MODEL}

This section describes the multivariable anaesthesia model combining the muscle relaxation and the depth of anaesthesia. Two drugs are used as inputs to the model, the atracurium (for producing muscle relaxation) and the isoflurane (for depth of anaesthesia) which is an inhalational drug commonly used in modern surgery. The individual pathways are described as follows [3]. 


\subsection{Atracurium Mathematical Model}

To identify the muscle relaxation process associated with atracurium drug, pharmacological modeling is commonly used to describe the metabolism of such drug. Pharmacological modeling comprises two main categories known as pharmacokinetics and pharmcodynamics. Pharmacokinetics studies the relationship that exists between drug dose and drug concentration in the blood plasma as well as other parts of the body. Interpretation of this relationship can be given a mathematical meaning via the concept of compartmental models. Using this concept the body consists of several compartments each representing one part of the body that involves the drug metabolism. Pharmacodynamics, however, is concerned with the drug concentration in the blood and the effect produced.

\subsubsection{Pharmacokinetics}

The pharmacokinetics studies what the body does to the drug. It has been shown that after a drug injection, the plasma concentration of atracurium declines rapidly in two exponential phases corresponding to distribution and elimination. Therefore, a conventional two compartmental model is used by adding an elimination path from the peripheral compartment as depicted in Fig.1.

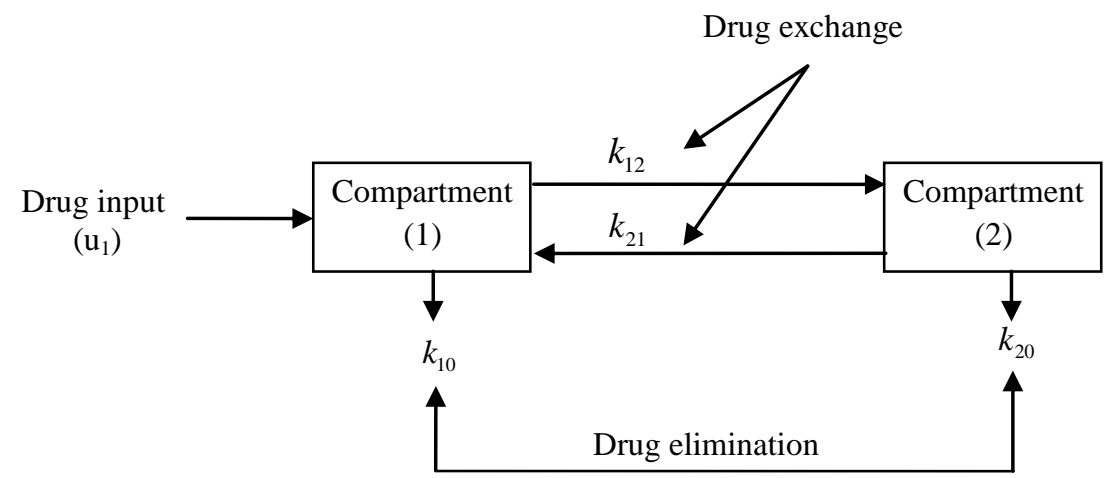

Fig.1: A two compartmental model for atracurium with an additional elimination path

Assume $x_{i}$ is the drug concentration at time $\mathrm{t}, \dot{x}_{i}$ its rate of change, and $u$ the drug input, then:

$$
\begin{aligned}
& \dot{x}_{1}=-\left(k_{10}+k_{12}\right) x_{1}+k_{21} x_{2}+u_{1} \\
& \dot{x}_{2}=k_{12} x_{1}-\left(k_{20}+k_{21}\right) x_{2}
\end{aligned}
$$

Using Laplace transform, equation (1) can be rewritten as:

$$
\begin{aligned}
& s X_{1}=-\left(k_{10}+k_{12}\right) X_{1}+k_{21} X_{2}+U_{1} \\
& s X_{2}=k_{12} X_{1}-\left(k_{20}+k_{21}\right) X_{2}
\end{aligned}
$$

Hence, 


$$
\frac{X_{1}(s)}{U_{1}(s)}=\frac{s+k_{20}+k_{21}}{\left(s+k_{10}+k_{12}\right)\left(s+k_{20}+k_{21}\right)-k_{12} k_{21}}
$$

Equation (3) can be written as:

$$
\frac{X_{1}(s)}{U_{1}(s)}=\frac{K\left(1+T_{4} s\right)}{\left(1+T_{1} s\right)\left(1+T_{2} s\right)}
$$

which describe the pharmacokinetics of the muscle relaxation system relating to the drug atracurium in a transfer function form. Where, $X_{1}$ and $U_{1}$ are the drug concentration in the blood and the drug input, respectively.

\subsubsection{Pharmacodynamics}

To identify the drug effect, a third compartment known as the "effect compartment" has been introduced to the atracurium kinetics. It is connected to the central compartment by a first order rate constant $k_{1 E}$, whereas the rate constant $k_{E 0}$ characterizes the drug dissipation from the effect compartment, as shown in Fig. 2.

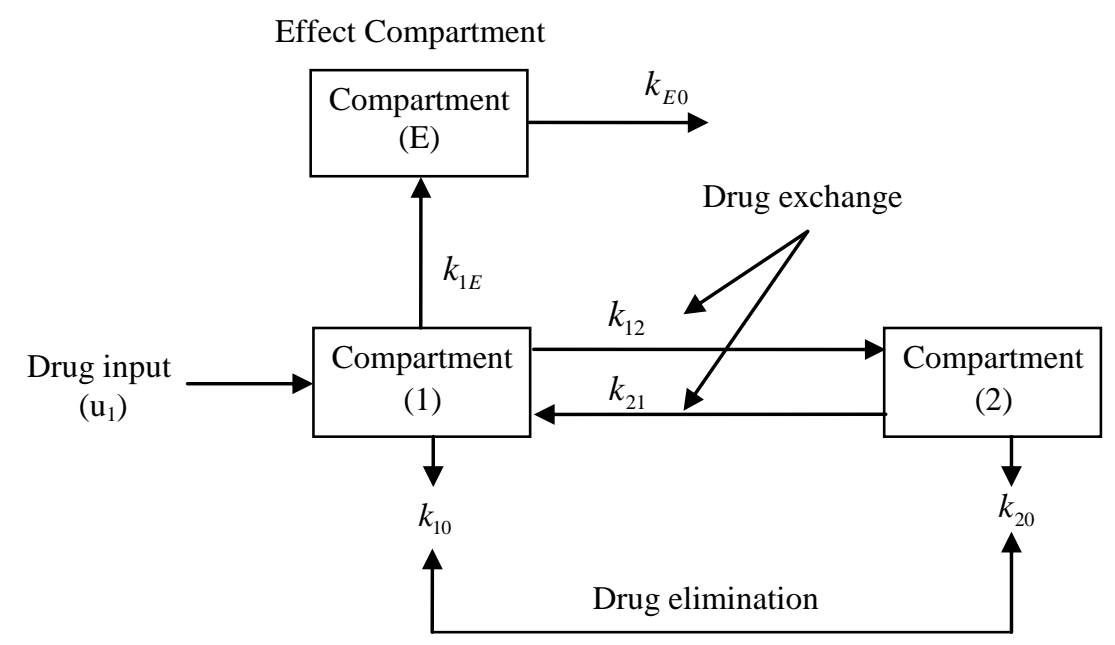

Fig. 2: Modification of the atracurium kinetics to include the effect compartment $\mathrm{E}$

In this latter compartment, the drug concentration change is governed by the following equation:

$$
\dot{x}_{E}=k_{1 E} x_{1}-k_{E 0} x_{E}
$$

Using Laplace transforms yields:

$$
X_{E}=\frac{k_{1 E} X_{1}}{s+k_{E 0}}
$$


The Hill equation may be used to relate the effect to a specific blood concentration of drug:

$$
E_{\text {eff }}=\frac{E_{\max }}{1+\frac{X_{E}(50)^{\alpha}}{X_{E}^{\alpha}}}
$$

Where $E_{\text {eff }}, E_{\max }, X_{E}(50)$ are the drug effect produced (paralysis), the maximum drug effect (100\% paralysis), and the drug concentration at 50\% effect, respectively. The values of $X_{E}(50)$ and $\alpha$ depend on the patient, where may be change from patient to other.

Combining equations (6) and (4) and normalizing the overall open-loop gain leads to:

$$
G_{11}(s)=\frac{X_{E}}{U_{1}}=\frac{K_{1} e^{-\tau_{1} s}\left(1+T_{4} S\right)}{\left(1+T_{1} s\right)\left(1+T_{2}\right)\left(1+T_{3} s\right)}
$$

Where the values of parameters $K_{1}, \tau_{1}, T_{1}, T_{2}, T_{3}$ and $T_{4}$ depend on the patient and may be change from patient to other. Finally, the overall nonlinear atracurium mathematical model is obtained by combining equation (8) together with Hill equation (7).

\subsection{Isoflurane Mathematical Model}

Depth of anaesthesia (Unconsciousness) is defined as being the state in which the body is insensitive to pain or other stimuli. There is no direct method of measuring depth of anaesthesia. Consequently, anaesthetists have to resort to the merger of several clinical signs such as blood pressure, respiration, etc. to obtain the closed possible indication of how well the patient is anaesthetized. Indeed, in a study conducted in [3], anaesthetists were asked to rank the relative importance of ten clinical signs. These signs were ranked on a scale 1 to 10 based on the mean value provided by these anaesthetists. From these ten clinical signs, blood pressure (in terms the change of the mean arterial blood pressure) has been selected as one variable to give indication of depth of anaesthesia.

The transfer function which described the variation of mean arterial blood pressure to small changes in inhaled isoflurane concentration is given by:

$$
G_{22}(s)=\frac{\triangle M A B P}{U_{2}}=\frac{K_{2} e^{-\tau_{2} s}}{\left(1+T_{5} s\right)}
$$

Where $\triangle M A B P$ is the change in the mean arterial blood pressure, $U_{2}$ is the isoflurane drug input, and the values of parameters $\tau_{2}, T_{5}$ and $K_{2}$ depend on the patient.

\subsection{Interactive Component Model}

\subsubsection{Atracurium to mean arterial blood pressure ( $\triangle M A B P$ ) interaction}

This interaction has been investigated in human begins and there seems to be small (clinically insignificant) changes in blood pressure. 


\subsubsection{Isoflurane to Muscle Relaxation Interaction}

In order to identify this type of interaction which is small but significant, an experiment was performed by Asburt [3]. As a result of this experiment, the overall describing the effect that isoflurane on muscle relaxation is given by:

$$
G_{12}(s)=\frac{K_{4} e^{-\tau_{3} s}}{\left(1+T_{6} s\right)\left(1+T_{7} s\right)}
$$

Where the values of parameters $K_{4}, \tau_{3}, T_{6}$ and $T_{7}$ depend on the patient.

\subsection{The Overall Multivariable Anaesthesia Model}

The overall linear multivariable system combining muscle relaxation together with anaesthesia (in terms of mean arterial blood pressure measurements) besides a nonlinear Hill equation is depicted in Fig. 3 [6]. Without including the nonlinear part, the linear multivariable anaesthesia can be summarized as follows:

$$
\left[\begin{array}{c}
\text { paralysis } \\
\Delta M A B P
\end{array}\right]=\left[\begin{array}{cc}
G_{11}(s) & G_{12}(s) \\
0 & G_{22}(s)
\end{array}\right]\left[\begin{array}{c}
U_{1} \\
U_{2}
\end{array}\right]
$$

where, $G_{11}(s), G_{22}(s)$ and $G_{12}(s)$ are defined in equations (8), (9), and (10). The two inputs, $U_{1}$ and $U_{2}$ are the atracurium and isoflurane drugs respectively.

Finally, the overall nonlinear multivariable system combining all the effects is obtained by including the nonlinearity described previously contained in the muscle relaxation path.

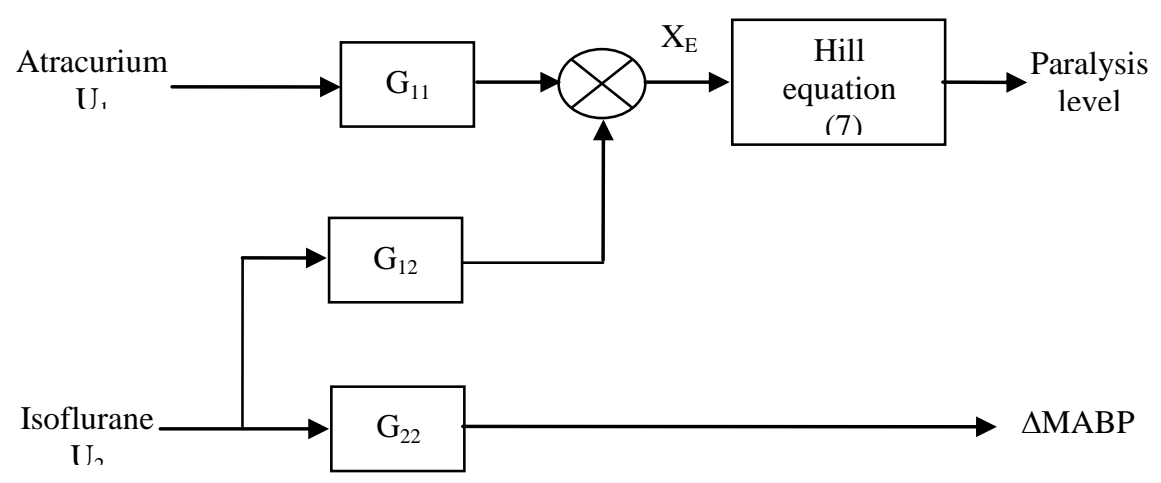

Fig. 3: The nonlinear model of the multivariable anaesthesia

\section{OVERVIEW OF TYPE-2 FUZZY LOGIC SYSTEMS}

\subsection{Type-2 fuzzy sets}

A type-2 fuzzy set (T2-FS), denoted $\tilde{A}$, is characterized by a type-2 membership function $\mu_{\tilde{A}}(x, v)$, where $x \in X$ and $v \in J_{x} \subseteq[0,1]$, i.e., [17] 


$$
\tilde{A}=\left\{\left((x, v), \mu_{\tilde{A}}(x, v)\right) \mid \forall x \in X, \forall v \in J_{x} \subseteq[0,1]\right\}
$$

in which $0 \leq \mu_{\tilde{A}}(x, v) \leq 1 . \tilde{A}$ can also be expressed as follows [17]:

$$
\tilde{A}=\int_{x \in X} \int_{v \in J_{x}} \mu_{\tilde{A}}(x, v) /(x, v) \quad J_{x} \subseteq[0,1]
$$

where $\iint$ denotes union over all admissible $x$ and $v \cdot \int$ is replaced by $\sum$ when the universe of discourse is discrete. For the above definition, the first restriction that $0 \leq \mu_{\tilde{A}}(x, v) \leq 1$ is consistent with the fact that the amplitudes of a membership function should lie between or be equal to 0 and 1 . The second restriction that $\forall v \in J_{x} \subseteq[0,1]$ is consistent with the type-1 constraint that $0 \leq \mu_{A}(x) \leq 1$, i.e., when uncertainties disappear a type-2 membership function must reduce to a type-1 membership function, in which case the variable $v$ equals $\mu_{A}(x)$ and $0 \leq \mu_{A}(x) \leq 1$.

\subsection{Interval Type-2 Fuzzy Sets}

An interval type-2 fuzzy set (IT2-FS) $\tilde{A}$ is characterized as [17]:

$$
\tilde{A}=\int_{x \in X} \int_{v \in J_{x} \subseteq[0,1]} 1 /(x, v)=\int_{x \in X}\left[\int_{v \in J_{x} \subseteq[0,1]} 1 / v\right] / x
$$

where $x$ is the primary variable and $x \in X ; v$ is the secondary variable, $v \in V$ and it has domain $J_{x}$ at each $x \in X ; J_{x}$ is called the primary membership of $x$ and is defined in equation (18); and, the secondary grades of $\tilde{A}$ all equal 1 . The union of all the primary memberships for fuzzy set $\tilde{A}$ is called the footprint of uncertainty (FOU) of $\tilde{A}$ (see Fig. 4) i.e.,

$$
F O U(\tilde{A})=\bigcup_{\forall x \in X} J_{x}=\left\{(x, v): v \in J_{x} \subseteq[0,1]\right\}
$$

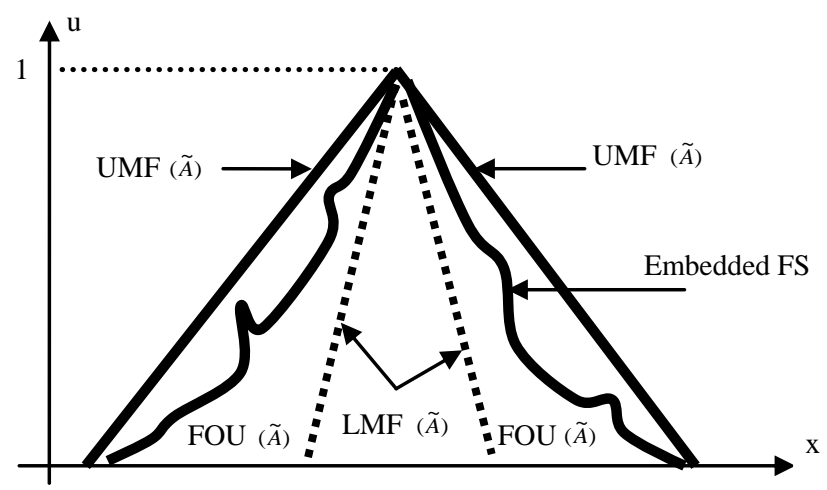

Fig. 4: Interval type-2 fuzzy set 
The upper membership function (UMF) and lower membership function (LMF) of $\tilde{A}$ are two type-1 MFs that bound the FOU. The UMF is associated with the upper bound of FOU $(\tilde{A})$ and is denoted $\bar{\mu}_{\tilde{A}}(x), \forall x \in X$, and the LMF is associated with the lower bound of FOU $(\tilde{A})$ and is denoted $\underline{\mu}_{\tilde{A}}(x)$, $\forall x \in X$, i.e.,

$$
\begin{aligned}
& \bar{\mu}_{\tilde{A}}(x)=\overline{F O U(\tilde{A})} \quad \forall x \in X \\
& \underline{\mu}_{\tilde{A}}(x)=\underline{\operatorname{FOU}(\tilde{A})} \quad \forall x \in X
\end{aligned}
$$

Note that $J_{x}$ is an interval set, i.e.,

$$
J_{x}=\left\{(x, v): v \in\left[\underline{\mu}_{\tilde{A}}(x), \bar{\mu}_{\tilde{A}}(x)\right]\right\}
$$

In this paper, the input and output variables will be represented by IT2FSs as they are simpler to work with than general T2-FSs and distribute the uncertainty evenly among all admissible primary memberships [18].

\subsection{Interval Type-2 Fuzzy Logic Controller}

In this section, we present the IT2-FLC that is used in this paper. The basics of fuzzy logic do not change from T1 to T2 sets, and in general, will not change for any type-n [19]. A higher-type number just indicates a higher "degree of fuzziness". Since a higher type changes the nature of the membership functions, the operation that depend on the membership functions change, however, the basic principle of fuzzy logic are independent of the nature of membership functions and hence, do not change [10].

The IT2-FLC contains four components fuzzifier, inference engine, rule base, and output processing that is inter-connected as shown in Fig. 5 [20]. The IT2-FLC works as follows [13]: the crisp input is first fuzzified into input IT2FSs. The input IT2-FSs then activate the inference engine and the rule base to produce output IT2-FSs. The IT2-FLC rules will remain the same as in T1-FLC, but the antecedents and/or the consequent will be represented by IT2-FSs. The IT2 fuzzy outputs of the inference engine are then processed by the type reducer, which combines the output sets and performs a centroid calculation that leads to T1-FSs called the type-reduced sets. After the type reduction process, the typereduced sets are defuzzified (by taking the average of the type-reduced set) to obtain crisp outputs.

\subsection{Computations in an IT2-FLC}

\subsubsection{IT2-FLC Fuzzification and Inference}

The calculations of the IT2-FLC are shown in Fig. 6. When $x_{1}=x_{1}^{\prime}$, the vertical line at $x_{1}^{\prime}$ intersects $\operatorname{FOU}\left(\tilde{A}_{1}\right)$ everywhere in the interval $\left[\underline{\mu}_{\tilde{A}_{1}}\left(x_{1}^{\prime}\right), \bar{\mu}_{\tilde{A}_{1}}\left(x_{1}^{\prime}\right)\right]$; 
and, when $x_{2}=x_{2}^{\prime}$, the vertical line at $x_{2}^{\prime}$ intersects $\operatorname{FOU}\left(\tilde{A}_{2}\right)$ everywhere in the interval $\left[\underline{\mu}_{\tilde{A}_{2}}\left(x_{2}^{\prime}\right), \bar{\mu}_{\tilde{A}_{2}}\left(x_{2}^{\prime}\right)\right]$. Two firing levels are then computed, a lower firing level, $f\left(x^{\prime}\right)$, and an upper firing level $\bar{f}\left(x^{\prime}\right)$, where $\underline{f}\left(x^{\prime}\right)=\min \left[\underline{\mu}_{\tilde{A}_{1}}\left(x_{1}^{\prime}\right), \underline{\mu}_{\tilde{A}_{2}}\left(x_{2}^{\prime}\right)\right]$ and $\bar{f}\left(x^{\prime}\right)=\min \left[\bar{\mu}_{\tilde{A}_{1}}\left(x_{1}^{\prime}\right), \bar{\mu}_{\tilde{A}_{2}}\left(x_{2}^{\prime}\right)\right]$. The main thing to observe from this figure is that the result of input and antecedent operations is the firing interval $F\left(x^{\prime}\right)$, where $F\left(x^{\prime}\right)=\left[\underline{f}\left(x^{\prime}\right), \bar{f}\left(x^{\prime}\right)\right] . \underline{f}\left(x^{\prime}\right)$ is tnormed with $\operatorname{LMF}(\tilde{B})$ and $\bar{f}\left(x^{\prime}\right)$ is t-normed with $\operatorname{UMF}(\tilde{B})$. When $\operatorname{FOU}(\widetilde{B})$ is triangular, and the t-norm is minimum, the resulting fired-rule $F O U$ is the trapezoidal $F O U$ as shown in figure.

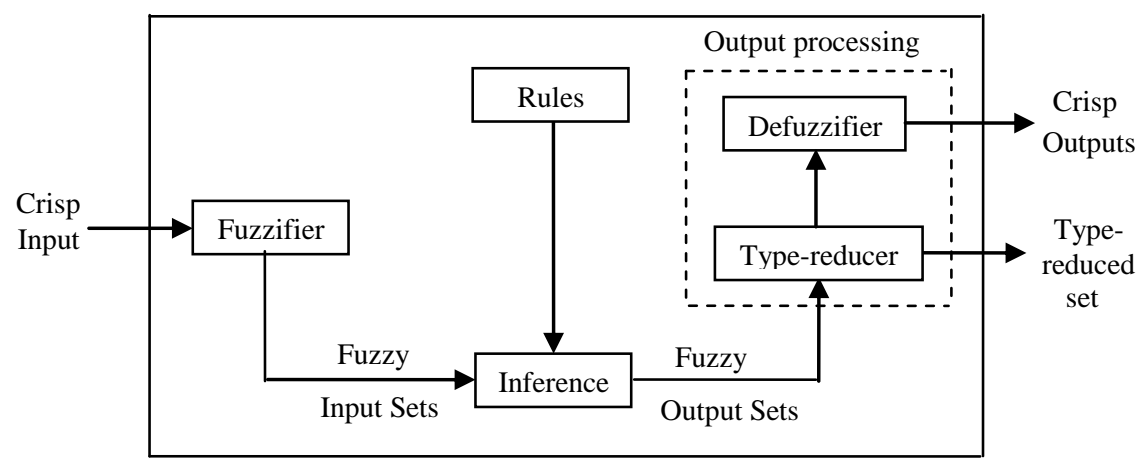

Fig. 5: Type-2 fuzzy logic controller

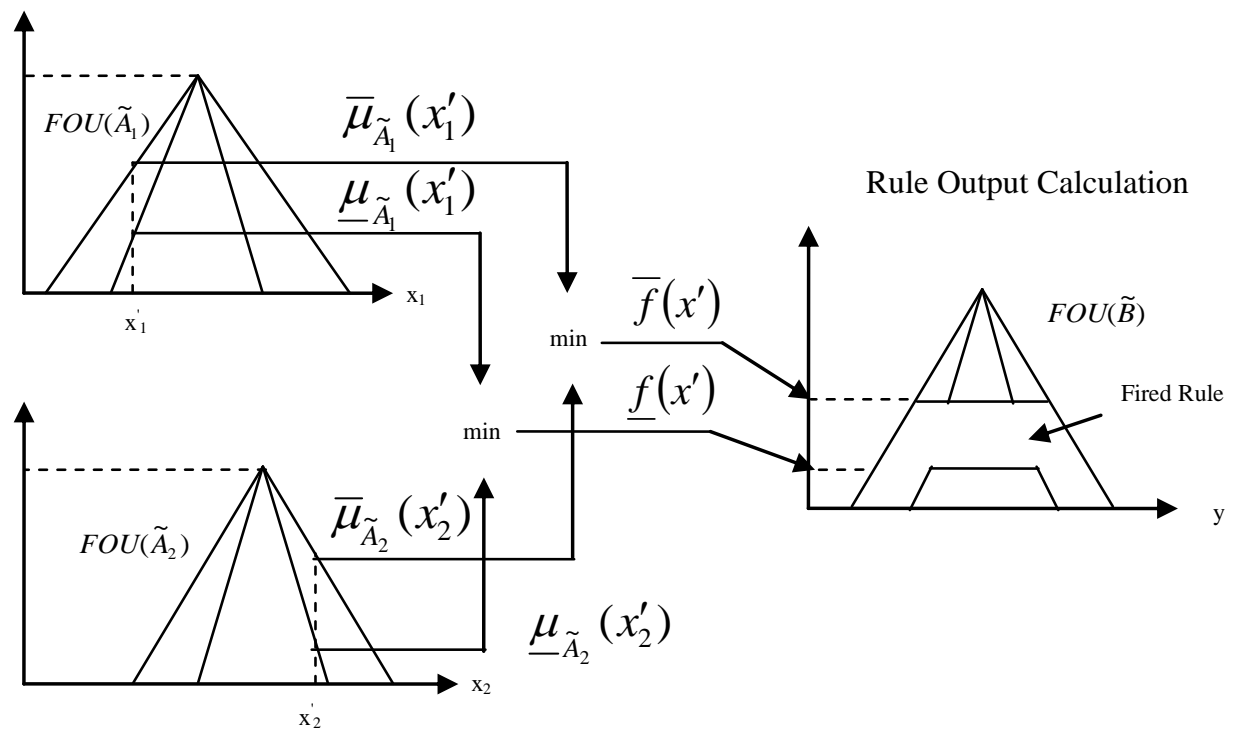

Fig. 6: IT2-FLC fuzzification and inference 


\subsubsection{Type-reduction}

In the IT2-FLC the output sets are type-2, so we have to use extended version of type-1 defuzzification methods. The extended defuzzification operation in the type- 2 case gives a T1-FS at the output. Since this operation takes us from the type-2 output sets of the IT2-FLC to a T1-FS, we call this operation typereduction and call the type-1 set so obtained a type-reduced set [19]. There are several methods of type-reduction. This paper uses the "center-of-sets" type reduction. The calculations of this method are performed as follows [20]:

- Compute the centroid of each rule's consequent IT2-FLC, using the KM algorithms [16]. Call it $\left[y_{l}^{l}, y_{r}^{l}\right](l=1, \ldots . M)$.

- Compute the firing interval of each fired rule. Call it $\left[\underline{f}^{l}, \bar{f}^{l}\right]$ $(l=1, \ldots . M)$.

- Compute $y_{\cos }(x)=\left[y_{l}(x), y_{r}(x)\right]$,where $y_{l}(x)$ is the solution to the following minimization problem and is defined in equation (19) and $y_{r}(x)$ is the solution to the following maximization problem and is defined in equation (20).

$$
\begin{aligned}
& y_{l}(x)=\min _{\forall f^{l} \in\left[\underline{f}^{l}, \bar{f}^{l}\right]}\left[\sum_{i=1}^{M} y_{l}^{l} f^{l} / \sum_{l=1}^{M} f^{l}\right] \\
& y_{r}(x)=\max _{\forall f^{l} \in\left[\underline{f}^{l}, \bar{f}^{l}\right]}\left[\sum_{i=1}^{M} y_{r}^{l} f^{l} / \sum_{l=1}^{M} f^{l}\right]
\end{aligned}
$$

\subsubsection{Defuzzification}

Defuzzification method used to convert type-reduced set to crisp output and it is performed by taking the average of $y_{l}(x)$ and $y_{r}(x)$.

\section{IT2-FLC FOR MULTIVARIABLE ANAESTHESIA SYSTEM}

\subsection{Multivariable Anaesthesia Control System}

Figure 7 shows a block diagram of a FLC with multivariable anaesthesia system. The FLC block in this figure may be T1-FLC or IT2-FLC. It have four inputs; the error signals $\left(e_{1}\right.$ and $\left.e_{2}\right)$ and the change in error signals $\left(\Delta e_{1}\right.$ and $\left.\Delta e_{2}\right)$, and two outputs: the control signal $\left(u_{1}\right)$ that is applied to syringe pump to produce the desired amount of drug 1 (Atracurium) and the control signal $\left(u_{2}\right)$ that is applied to vaporizer to produce the desired amount of drug 2 (Isofurane). EMG sensor is used to produce the EMG signal which represents the muscle relaxation (paralysis level) and then, it is compared with set-point $\left(\operatorname{Ref}_{1}\right)$ to obtain $e_{1}$. The blood pressure sensor is used to produce the $\triangle M A B P$ signal that is compared with set-point $\left(\operatorname{Ref}_{2}\right)$ to obtain $e_{2}$. 


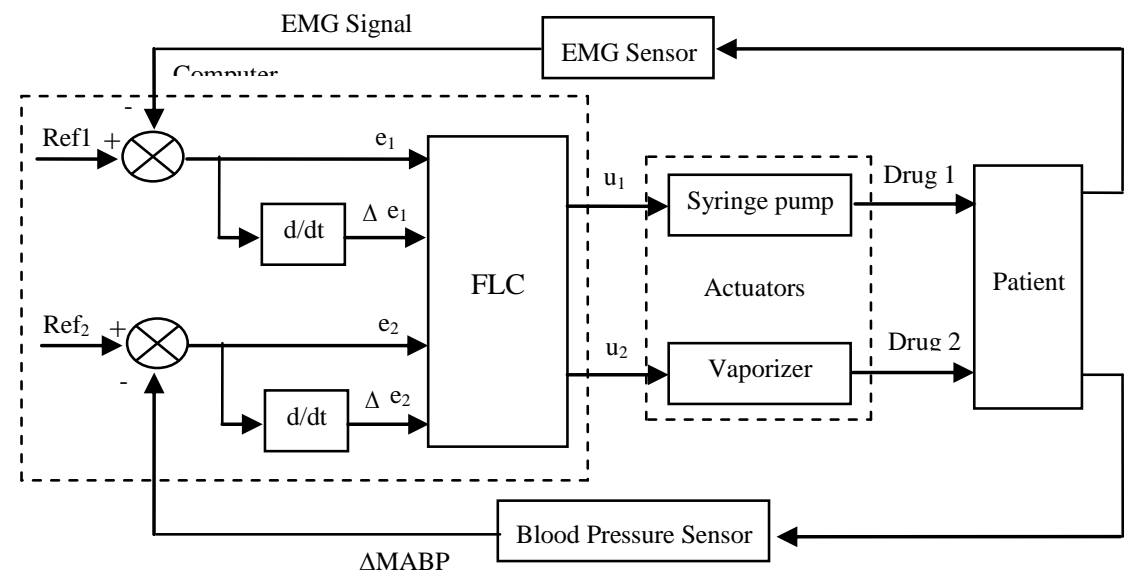

Fig. 7: The overall multivariable anaesthesia control system

\subsection{Structure of IT2-FLC}

The inputs and outputs membership functions for T1-FLC and IT2-FLC are shown in Figures 8 and 9 respectively. Each input and output of FLC is consist of five linguistic labels; negative big (NB), negative medium (NM), negative small (NS), zero (Z), positive small (PS), positive medium (PM), positive big (PB), small (S), medium (M), and Big (B). The rule base for control signals $u_{1}$ and $u_{2}$ are shown in Tables 1 and 2 respectively. $u_{1}$ and $u_{2}$ are calculated by using the "center-of-sets" type reduction that described above in section 3.4.2 and then we perform defuzzification that described earlier in section 3.4.3.
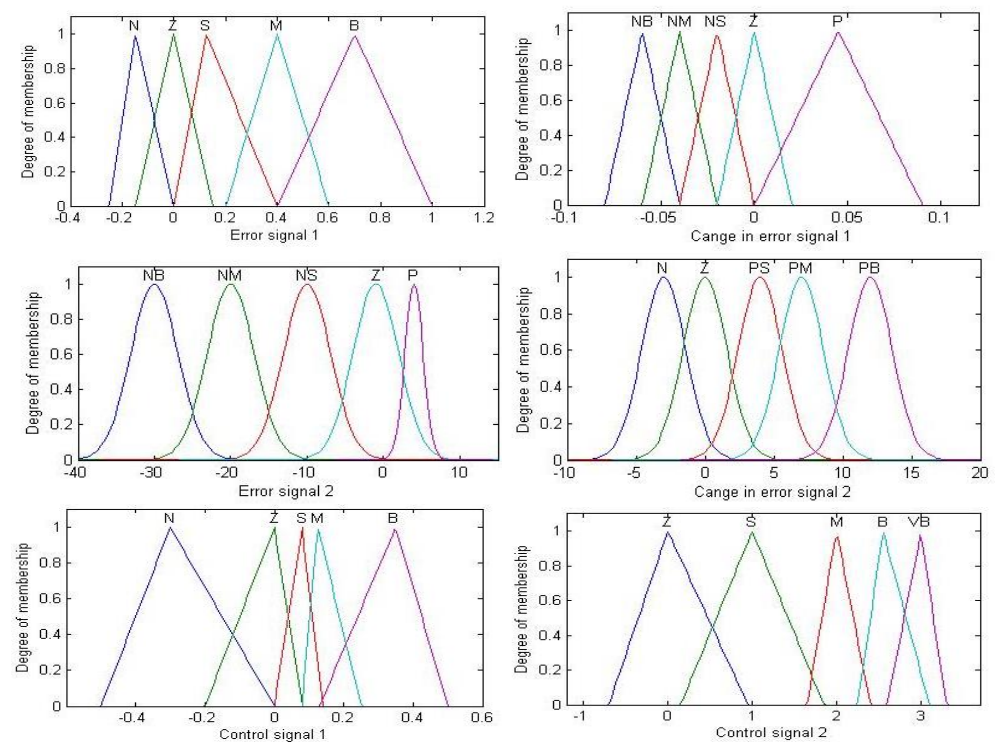

Fig. 8: The inputs and outputs MFs of T1-FLC 

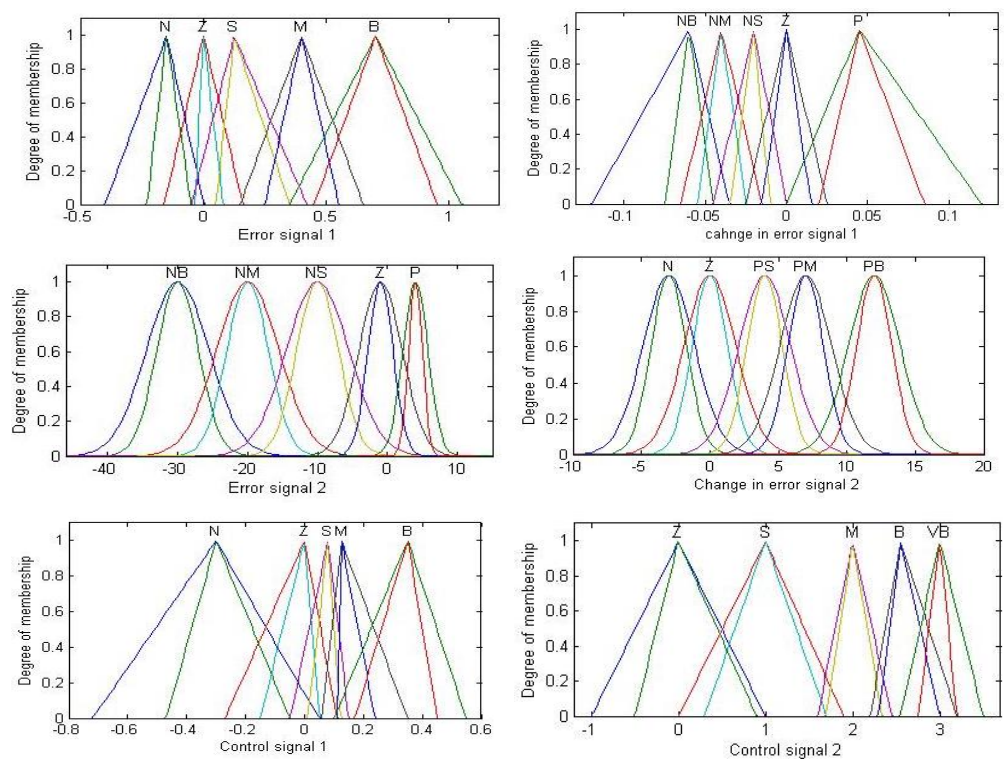

Fig. 9: The inputs and outputs MF of IT2-FLC

Table 1: Rule based for control signal 1 Table 2: Rule based for control signal 2

\begin{tabular}{|c|c|c|c|c|c|}
\hline $\mathbf{C E}_{\mathbf{1}} \mathbf{E}_{\mathbf{1}}$ & $\mathbf{N}$ & $\mathbf{Z}$ & $\mathbf{S}$ & $\mathbf{M}$ & $\mathbf{B}$ \\
\hline $\mathbf{N B}$ & $\mathrm{N}$ & $\mathrm{Z}$ & $\mathrm{M}$ & $\mathrm{B}$ & $\mathrm{B}$ \\
\hline $\mathbf{N M}$ & $\mathrm{N}$ & $\mathrm{S}$ & $\mathrm{M}$ & $\mathrm{B}$ & $\mathrm{B}$ \\
\hline $\mathbf{N S}$ & $\mathrm{N}$ & $\mathrm{S}$ & $\mathrm{B}$ & $\mathrm{B}$ & $\mathrm{B}$ \\
\hline $\mathbf{Z}$ & $\mathrm{N}$ & $\mathrm{M}$ & $\mathrm{B}$ & $\mathrm{B}$ & $\mathrm{B}$ \\
\hline $\mathbf{P}$ & $\mathrm{Z}$ & $\mathrm{M}$ & $\mathrm{B}$ & $\mathrm{B}$ & $\mathrm{B}$ \\
\hline
\end{tabular}

\begin{tabular}{|c|c|c|c|c|c|}
\hline $\mathbf{C E}_{2}$ & $\mathbf{N B}$ & $\mathbf{N M}$ & $\mathbf{N S}$ & $\mathbf{Z}$ & $\mathbf{P}$ \\
\hline $\mathbf{N}$ & VB & VB & B & M & S \\
\hline $\mathbf{Z}$ & VB & VB & B & M & S \\
\hline PS & VB & B & B & M & S \\
\hline PM & VB & B & B & M & Z \\
\hline PB & VB & B & M & M & Z \\
\hline
\end{tabular}

\section{SIMULATION RESULTS}

In this section we apply T1-FLC as another technique to anaesthesia model that described in section 2 and also we apply the proposed controller (IT2-FLC) to the same model and then compare the proposed controller with T1-FLC. Anaesthestic drugs normally have stable and slow acting response, consequently, step response is the most common identification procedure used by clinicians [3]. The set-point in the anaesthesia system is specified by the anaesthetist and will be approached as closely as possible during the maintenance of anaesthesia [21]. In these simulation tasks, the sampling period was $1 \mathrm{~min}$, the initial conditions were $0 \%$ paralysis (100\% EMG), the set-point command signal was 0.8 (80\% paralysis $-20 \% \mathrm{EMG}$ ) for muscle relaxation, and $-30 \mathrm{mmHg}$ for the change in the mean arterial blood pressure $(\triangle M A B P)$. These values of set-point for the muscle relaxation and the mean arterial blood pressure were used practically in [3]. The control signal 1 was limited between 0 and 1 for the atracurium drug 
input and between $0 \%$ and $5 \%$ for the isoflurane input (control signal 2). For anaesthesia system, the control objective is to attain and maintain an adequate of anaestrhetic level without any overshoot. This is the maintaining of a steady level of muscle relaxation and blood pressure with minimum deviation from set-point $[3,21]$.

\section{Task 1: Normal Case}

It concerns with the controller performance when the multivariable parameters are set to its nominal values, which are $\left(\mathrm{K}_{1}=1.0, \tau_{1}=1 \mathrm{~min}, T_{1}=4.81 \mathrm{~min}\right.$, $T_{2}=34.42 \mathrm{~min}, T_{3}=3.08 \mathrm{~min}, T_{4}=10.64 \mathrm{~min}, \tau_{2}=25 \mathrm{sec}, T_{5}=2 \mathrm{~min}$, $K_{2}=-15 \mathrm{mmhg} \%, K_{4}=0.27, \tau_{3}=1 \mathrm{~min}, T_{6}=1.25 \mathrm{~min}, T_{7}=2.83$ $\min , X_{E}(50)=0.404 \mu g m l^{-1}$, and $\alpha=2.98$ ) [3].

Figure 10 shows the response of multivariable anaesthesia system in normal case for T1-FLC and IT2-FLC. It is clear that a good performance for muscle relaxation and blood pressure in both T1-FLC and IT2-FLC.
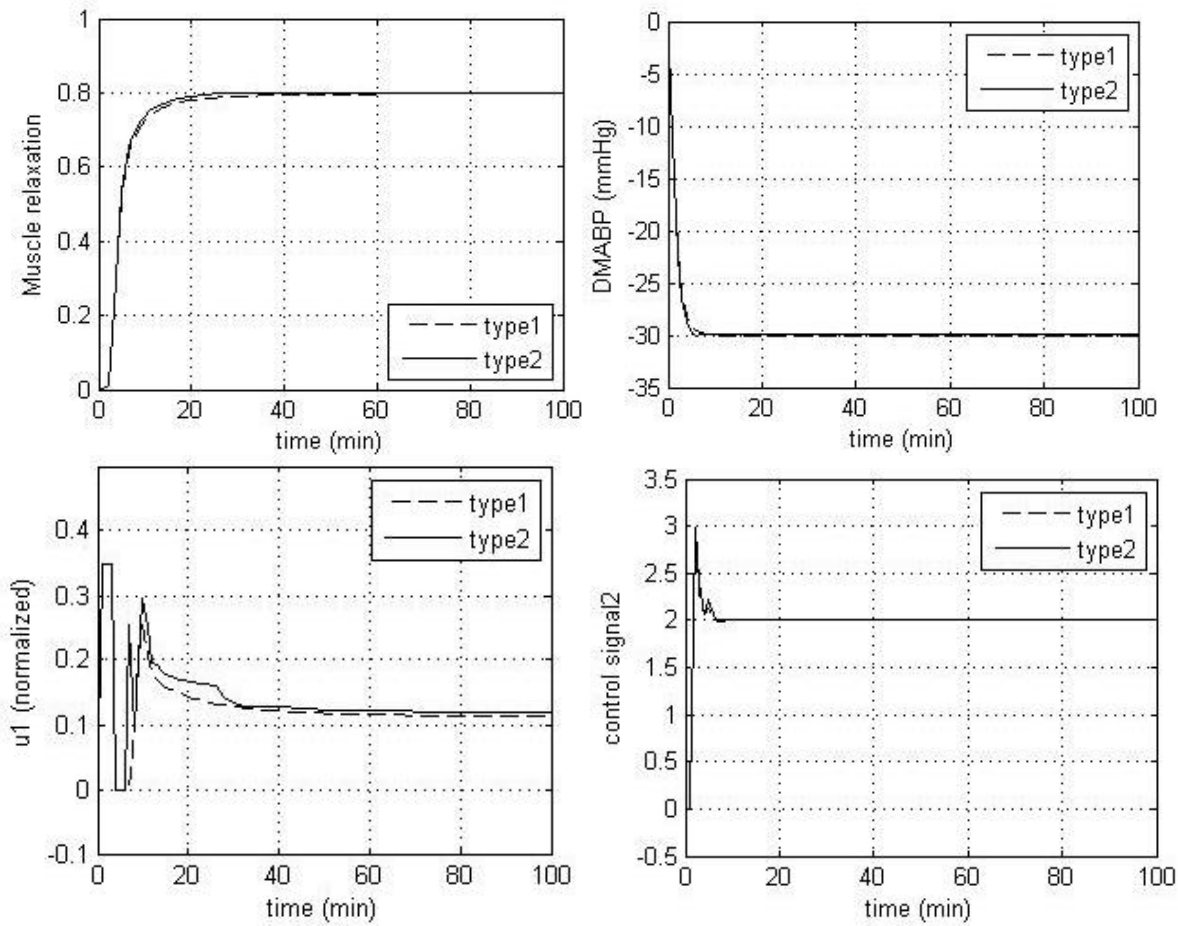

Fig. 10: The response of multivariable anaesthesia system (Task 1)

\section{Task 2: Disturbance in Blood Pressure}

In blood pressure, the disturbance can be related to the use of stimuli, such as the Surgeon's knife when cutting tissue which tends to make the blood pressure rise to undesired values. These values may be rise to $20 \mathrm{mmHg}$ [22]. This task shows the effect of disturbance of $9 \mathrm{mmHg}$ in the blood pressure for both T1-FLC and 
IT2-FLC. The system response for this task is shown in Fig. 11. The response of muscle relaxation and blood pressure for IT2-FLC is better than the results of T1FLC under the effect of disturbance because the mean arterial blood pressure exceed to the limit of constraint, where the maximum $\triangle M A B P$ is 0 .

\section{Task 3: The Inter-Individual Variability of the Patient's Parameters with Disturbance in Blood Pressure}

In this test the parameters changes from patient to patient with the effect of disturbance of $9 \mathrm{mmHg}$ in the blood pressure for T1-FLC and IT2-FLC. The model parameters are chosen in a random manner using the Monte-Carlo method [3]. The model parameters can be chosen according to the following formula:

$$
\text { par } \left.=\text { par }_{\min }+\text { Randon }_{\left(p a r_{\max }\right.}-\text { par }_{\min }\right)
$$

Where $0<$ Random $<1$, and is obtained from a random number generator. The $p a r_{\min }$ and $p a r_{\max }$ values for each parameter were chosen reflect probable pharmacological ranges known to exist. In this way many combinations could be produced. According to this method, we have ten cases in parameters changes [3]. In this paper, we selected only three of these to be presented for discussion.
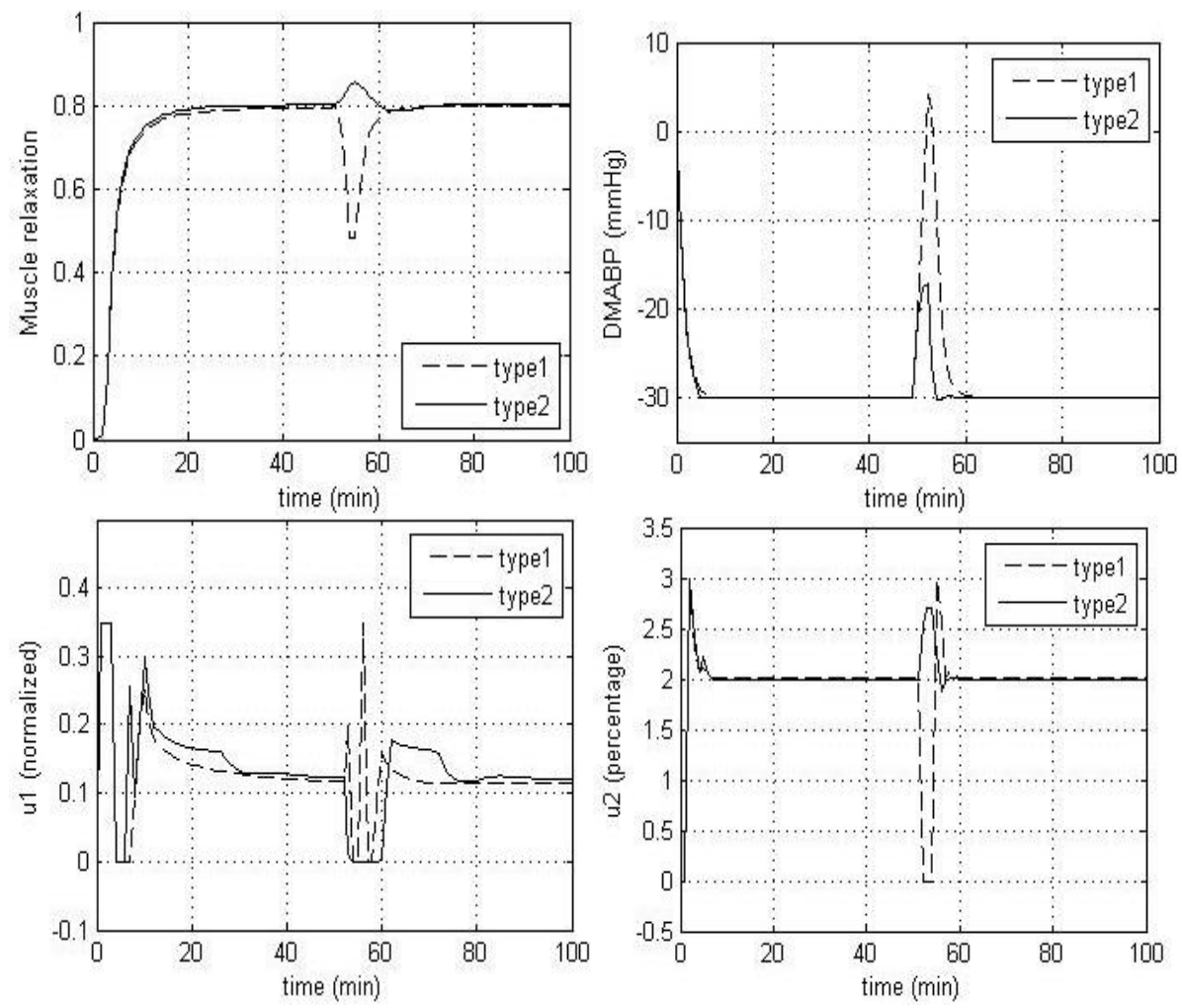

Fig. 11: The response of multivariable anaesthesia system (Task 2) 
Case1: $\mathrm{K}_{1}=2.08, \tau_{1}=1 \mathrm{~min}, T_{1}=1.55 \mathrm{~min}, T_{2}=32.74 \mathrm{~min}, T_{3}=2.58 \mathrm{~min}$, $T_{4}=13.31 \mathrm{~min}, \tau_{2}=25 \mathrm{sec}, T_{5}=1.26 \mathrm{~min}, K_{2}=-15.02 \mathrm{mmhg} \%, K_{4}=$ $0.25, \tau_{3}=1 \mathrm{~min}, T_{6}=1.24 \mathrm{~min}, T_{7}=2.85 \mathrm{~min}, X_{E}(50)=0.515 \mu \mathrm{gm} t^{-1}$, and $\alpha=2.98$.

Figure 12 shows the system response for this case. The performance of muscle relaxation in IT2-FLC is better than the results of T1-FLC under the effect of parameters change because there is a deviation from set-point with T1FLC. But, a good performance of blood pressure for both T1-FLC and IT2-FLC. IT2-FLC is better one under the effect of disturbance for both muscle relaxation and blood pressure because the mean arterial blood pressure exceed to the limit of constraint.
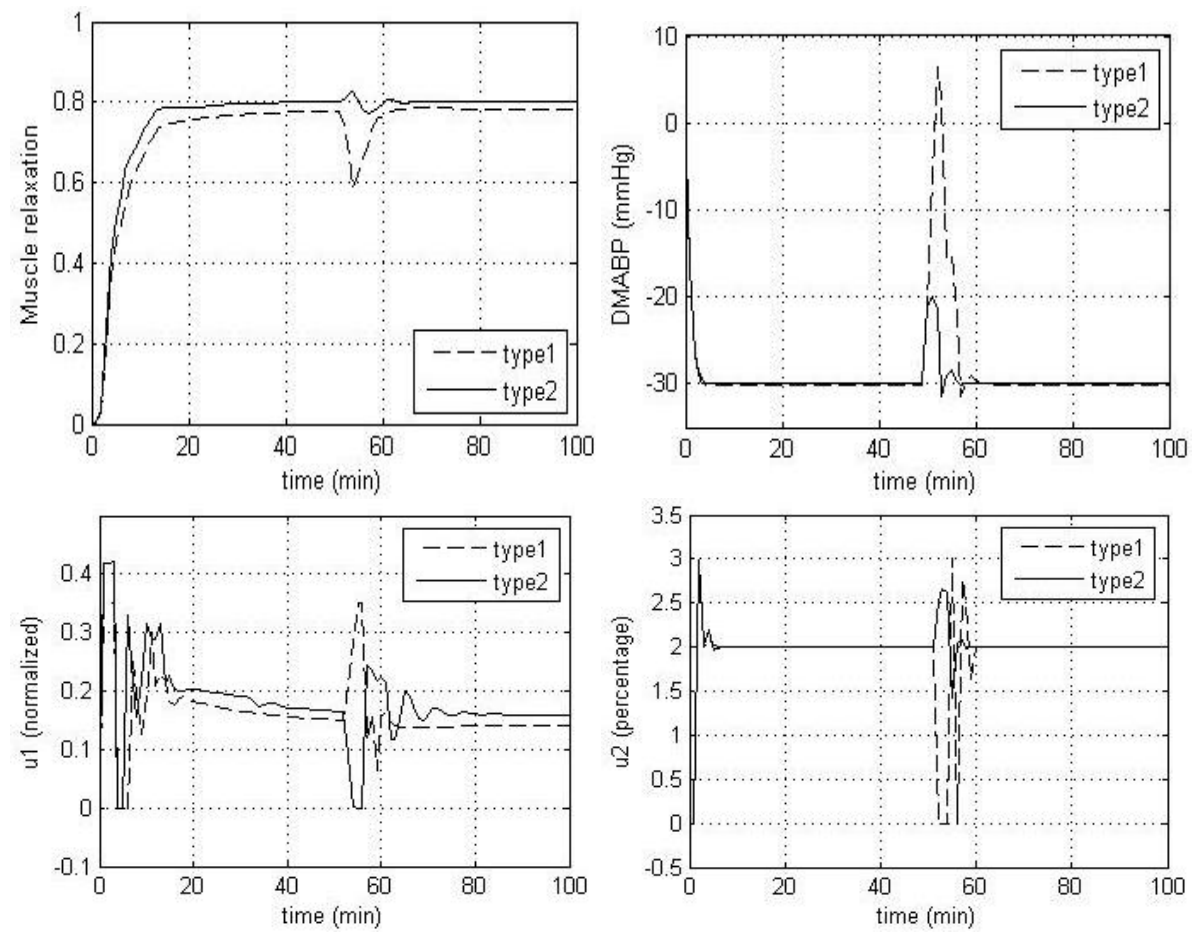

Fig. 12: The response of multivariable anaesthesia system (Task 3, Case 1)

Case2: $\mathrm{K}_{1}=2.16, \tau_{1}=1 \mathrm{~min}, T_{1}=2.35 \mathrm{~min}, T_{2}=27.88 \mathrm{~min}, T_{3}=2.95 \mathrm{~min}$, $T_{4}=10.88 \mathrm{~min}, \tau_{2}=25 \mathrm{sec}, T_{5}=1.15 \mathrm{~min}, K_{2}=-14.61 \mathrm{~mm} \mathrm{hg} / \%, K_{4}=$ $0.24, \tau_{3}=1 \mathrm{~min}, T_{6}=1.26 \mathrm{~min}, T_{7}=3.06 \mathrm{~min}, X_{E}(50)=0.5 \mu g m l^{-1}$, and $\alpha=2.98$.

Figure 13 shows the system response for this case. The performance of muscle relaxation is the same as in case 1 . There is a small deviation from setpoint in blood pressure in both T1-FLC and IT2-FLC. But, IT2-FLC is better one under the effect of disturbance. 

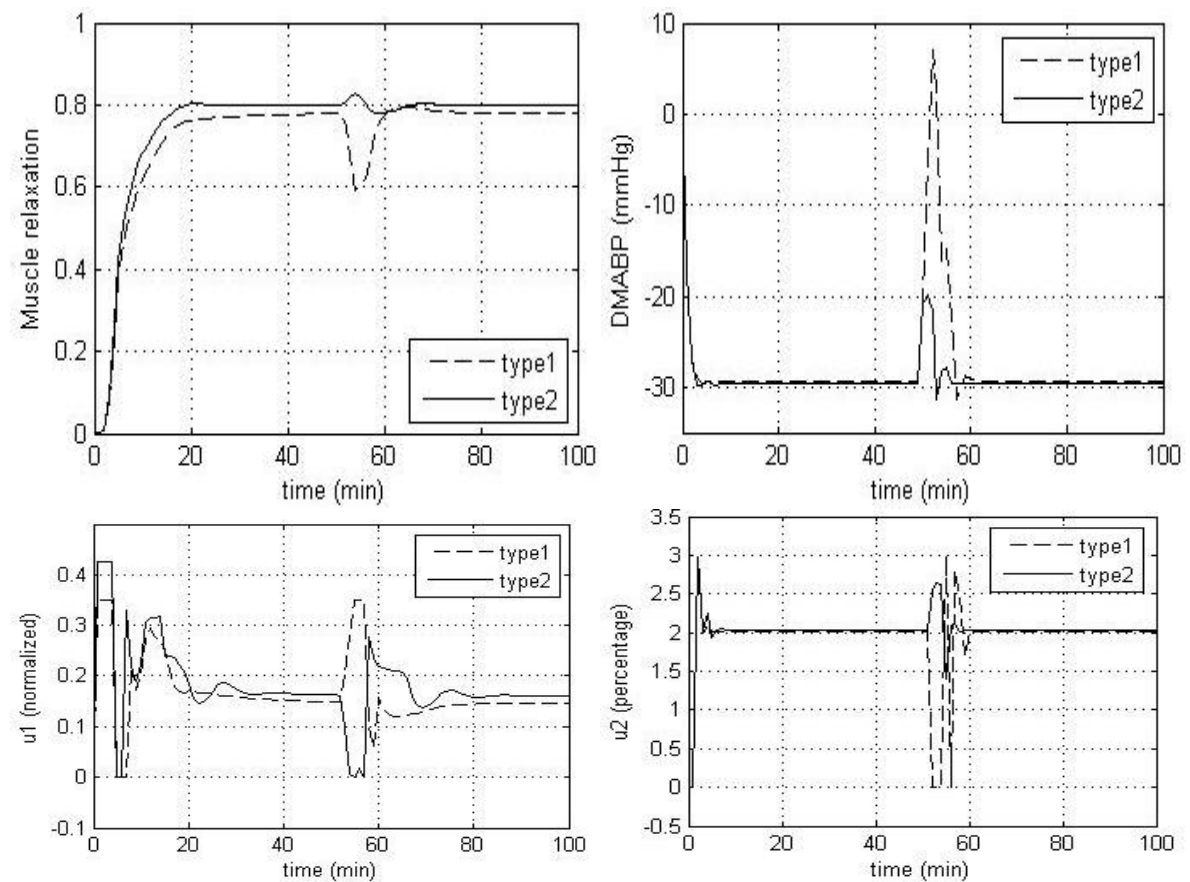

Fig. 13: The response of multivariable anaesthesia system (Task 3, Case 2)

Case3: $\mathrm{K}_{1}=1.33, \tau_{1}=1 \mathrm{~min}, T_{1}=1.91 \mathrm{~min}, T_{2}=34.22 \mathrm{~min}, T_{3}=4.06 \mathrm{~min}$, $T_{4}=7.31 \mathrm{~min}, \tau_{2}=25 \mathrm{sec}, T_{5}=1.37 \mathrm{~min}, K_{2}=-14.09 \mathrm{mmhg} \%, K_{4}=$ $0.25, \tau_{3}=1 \mathrm{~min}, T_{6}=1.21 \mathrm{~min}, T_{7}=2.71 \mathrm{~min}, X_{E}(50)=0.42 \mu g m t^{-1}$, and $\alpha=2.98$.

The system response of this case is shown in Fig. 14. The performance of two outputs is the same as in case 2 .

\section{Task 4: Simulation in a Noise Environment}

In this task a noise sequence of $1 \%$ and $3 \mathrm{mmHg}$ peak for muscle relaxation and blood pressure respectively were considered. These values of noise used practically in [3]. The response of the system in this case is shown in Fig. 15. It is clear that the IT2-FLC has a good performance for muscle relaxation and blood pressure rather than T1-FLC under the effect of environmental noise because the mean arterial blood pressure exceed to the limit of constraint. 

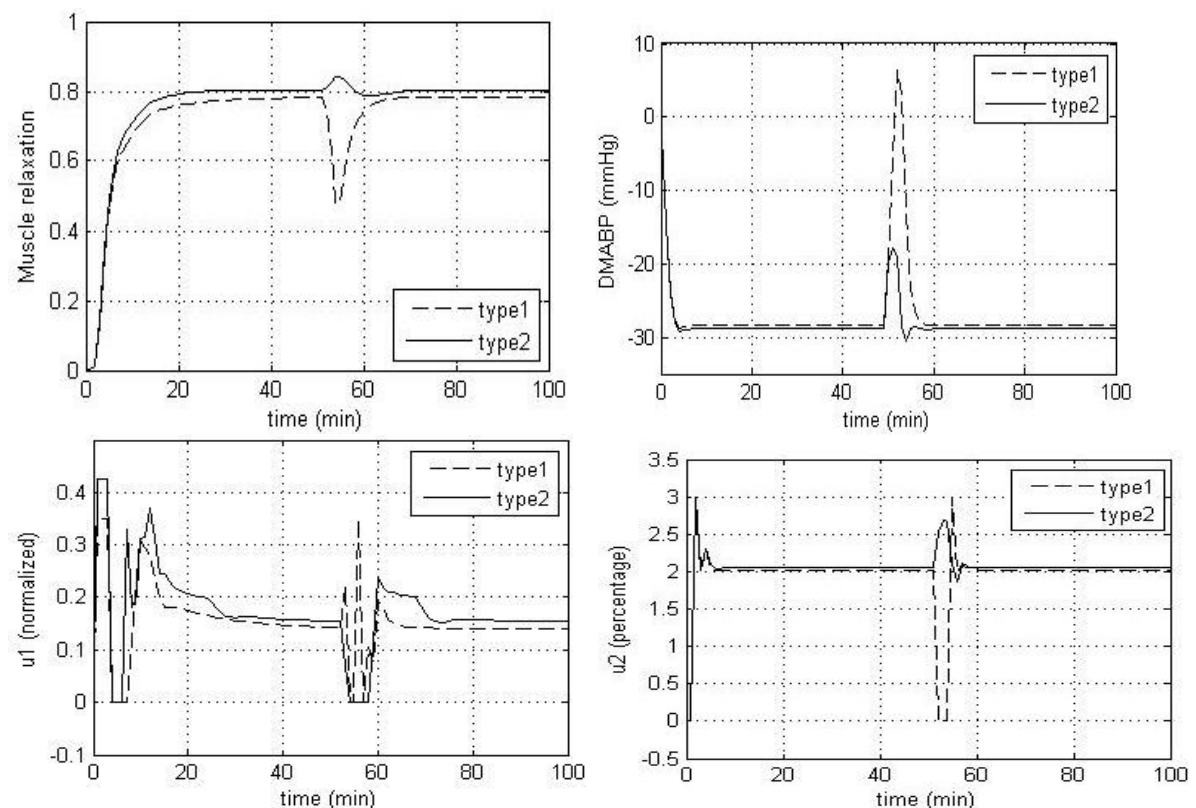

Fig. 14: The response of multivariable anaesthesia system (Task 3, Case 3)
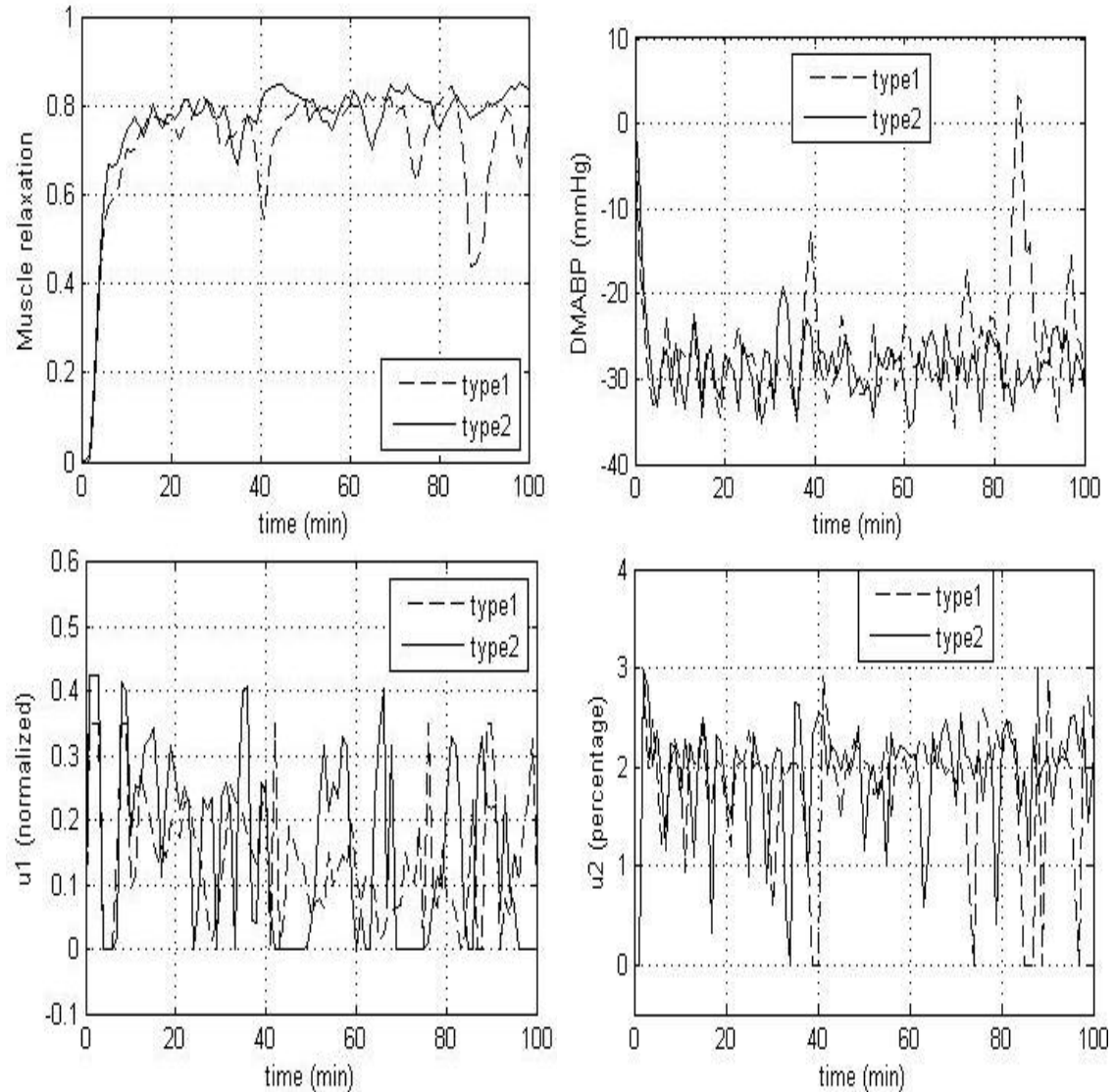

Fig. 15: The response of multivariable anaesthesia system under noise effect (Task 4) 


\section{Task 5: The Intra-Individual Variability of the Patient's Parameters}

In this task the parameters changes for the patient during surgery. For the first 100 samples the parameters are same as nominal values and the last 100 samples the parameters changes as $\mathrm{K}_{1}=1.33, \tau_{1}=1 \mathrm{~min}, T_{1}=1.91 \mathrm{~min}, T_{2}=34.22 \mathrm{~min}$, $T_{3}=4.06 \mathrm{~min}, T_{4}=7.31 \mathrm{~min}, \tau_{2}=25 \mathrm{sec}, T_{5}=1.37 \mathrm{~min}$, $K_{2}=-15 \mathrm{mmhg} \%, K_{4}=0.27, \tau_{3}=1 \mathrm{~min}, T_{6}=1.25 \mathrm{~min}, T_{7}=2.83 \mathrm{~min}$, $X_{E}(50)=0.42 \mu g m l^{1}$, and $\alpha=2.98$. Figure 16 shows the system response in this task. The performance of muscle relaxation for IT2-FLC is better than T1FLC because there is a deviation from set-point with T1-FLC. It is clear that, a good performance for blood pressure for both T1-FLC and IT2-FLC.
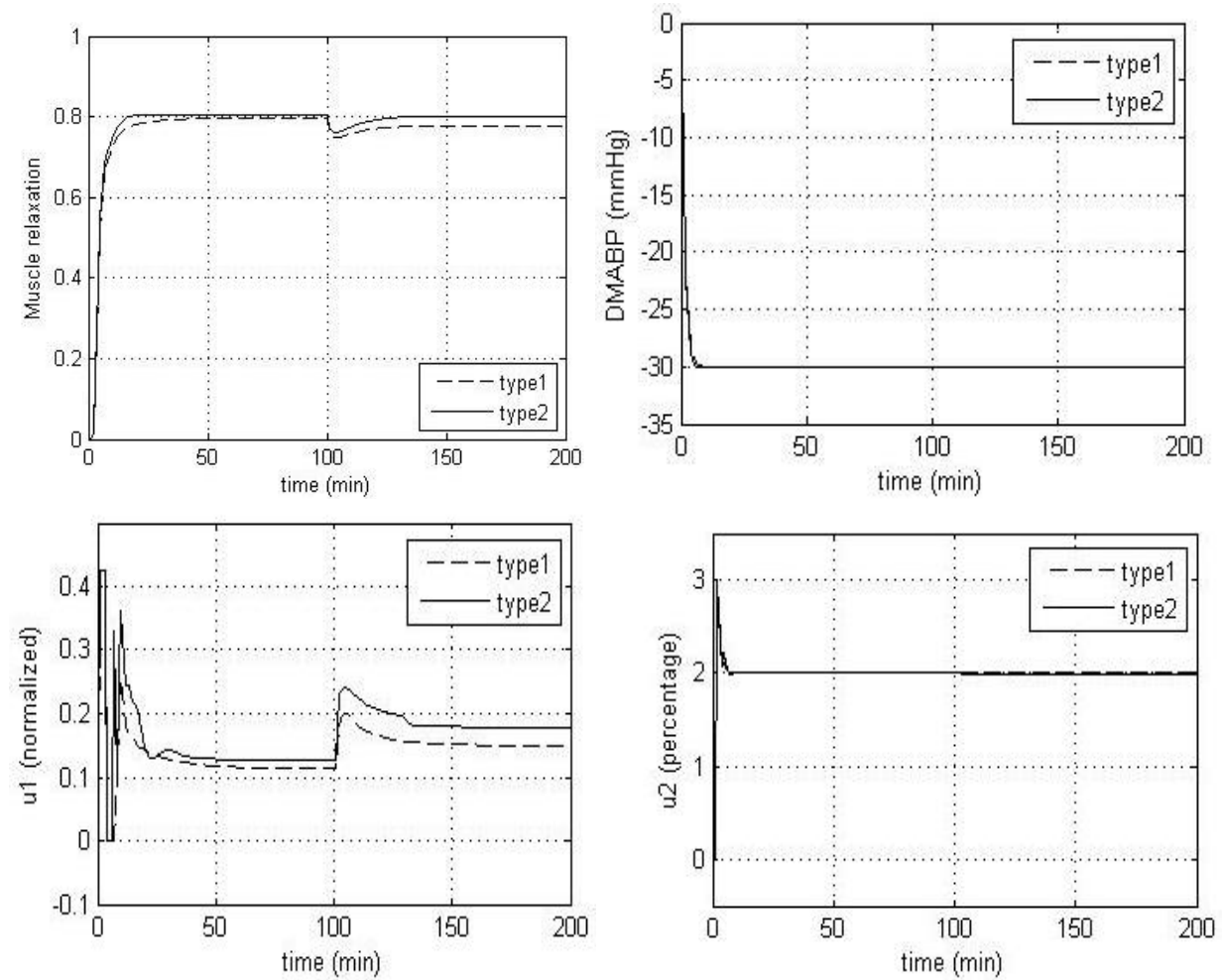

Fig. 16: The response of multivariable anaesthesia system (Task 5)

To show the visual indications of control performance, an objective measure of error performance over the simulation run was made using integral of square of errors (ISE), integral of time and absolute error (ITAE) and root mean square error (RMSE) criteria. ISE, ITAE and RMSE are defined in equations (22), (23) and (24) respectively. Tables 3, 4 and 5 list the ITAE, ISE and RMSE values for the T1-FLC and IT2-FLC respectively for all the above tasks simulation. The unit of time for the ITAE criterion was minutes in each case. The criteria were evaluated over the whole 100 minutes run in the first four tasks and over the whole 200 minutes run in the task 5 . 


$$
\begin{aligned}
& I S E=\int_{0}^{\infty}[e(t)]^{2} d t \\
& I T A E=\int_{0}^{\infty} t \mid e(t) d t \\
& \text { RMSE }=\sqrt{\frac{1}{N} \sum_{i=1}^{N}(e(t))^{2}}
\end{aligned}
$$

In general, for the blood pressure the ITAE, ISE and RMSE values were greater than for muscle relaxation, simply because of non-normalized values for blood pressure. As shown in the tables all the ITAE, ISE and RMSE values obtained with IT2-FLC are lower than those obtained using T1-FLC.

Table 3: The ITAE values of the T1-FLC and IT2-FLC for multivariable anaesthesia system

\begin{tabular}{|c|c|c|c|c|}
\hline \multirow{2}{*}{ Tasks } & \multicolumn{2}{|c|}{ T1-FLC } & \multicolumn{2}{c|}{ IT2-FLC } \\
\cline { 2 - 5 } & $\begin{array}{c}\text { ITAE } \\
\text { Muscle } \\
\text { Relaxation }\end{array}$ & $\begin{array}{c}\text { ITAE } \\
\text { Blood } \\
\text { Pressure }\end{array}$ & $\begin{array}{c}\text { ITAE } \\
\text { Muscle } \\
\text { Relaxation }\end{array}$ & $\begin{array}{c}\text { ITAE } \\
\text { Blood } \\
\text { Pressure }\end{array}$ \\
\hline Task 1 & 38.5 & 341.9 & 27.5 & 253.8 \\
\hline Task 2 & 113 & 7434 & 45 & 2270 \\
\hline Task 3 (case 1) & 169.4 & 8091 & 33.7 & 1779 \\
\hline Task 3 (case 2) & 175.8 & 10943 & 41.56 & 3304 \\
\hline Task 3 (case 3) & 195.3 & 14710 & 43.3 & 7322 \\
\hline Task 4 & 374.36 & 29341 & 154.8 & 14528 \\
\hline Task 5 & 416 & 1604 & 111 & 374.6 \\
\hline
\end{tabular}

Table 4: The ISE values of the T1-FLC and IT2 FLC for multivariable anaesthesia system

\begin{tabular}{|c|c|c|c|c|}
\hline \multirow{2}{*}{ Tasks } & \multicolumn{2}{|c|}{ T1-FLC } & \multicolumn{2}{c|}{ IT2-FLC } \\
\cline { 2 - 5 } & $\begin{array}{c}\text { ISE } \\
\text { Muscle } \\
\text { Relaxation }\end{array}$ & $\begin{array}{c}\text { ISE } \\
\text { Blood } \\
\text { Pressure }\end{array}$ & $\begin{array}{c}\text { ISE } \\
\text { Muscle } \\
\text { Relaxation }\end{array}$ & $\begin{array}{c}\text { ISE } \\
\text { Blood } \\
\text { Pressure }\end{array}$ \\
\hline Task 1 & 2.7 & 1333 & 2.6 & 1323 \\
\hline Task 2 & 2.9 & 4608 & 2.65 & 1737 \\
\hline Task 3 (case 1) & 3.02 & 4656 & 2.54 & 1351 \\
\hline Task 3 (case 2) & 3.5 & 4765 & 3.05 & 1347 \\
\hline Task 3 (case 3) & 3.2 & 4907 & 2.76 & 1667 \\
\hline Task 4 & 3.65 & 6543 & 2.64 & 2910 \\
\hline Task 5 & 2.76 & 1333 & 2.61 & 1323 \\
\hline
\end{tabular}


Table 5: The RMSE values of the T1-FLC and IT2 FLC for multivariable anaesthesia system

\begin{tabular}{|c|c|c|c|c|}
\hline \multirow{2}{*}{ Tasks } & \multicolumn{2}{|c|}{ T1-FLC } & \multicolumn{2}{c|}{ IT2-FLC } \\
\cline { 2 - 5 } & $\begin{array}{c}\text { RMSE } \\
\text { Muscle } \\
\text { Relaxation }\end{array}$ & $\begin{array}{c}\text { RMSE } \\
\text { Blood } \\
\text { Pressure }\end{array}$ & $\begin{array}{c}\text { RMSE } \\
\text { Muscle } \\
\text { Relaxation }\end{array}$ & $\begin{array}{c}\text { RMSE } \\
\text { Blood } \\
\text { Pressure }\end{array}$ \\
\hline Task 1 & 0.164 & 3.65 & 0.161 & 3.63 \\
\hline Task 2 & 0.170 & 6.788 & 0.162 & 4.167 \\
\hline Task 3 (case 1) & 0.173 & 6.82 & 0.159 & 3.68 \\
\hline Task 3 (case 2) & 0.187 & 6.90 & 0.174 & 3.67 \\
\hline Task 3 (case 3) & 0.178 & 7.00 & 0.166 & 4.08 \\
\hline Task 4 & 0.191 & 8.09 & 0.162 & 5.39 \\
\hline Task 5 & 0.117 & 2.58 & 0.114 & 2.57 \\
\hline
\end{tabular}

\section{CONCLUSION}

In this paper, we have tested the proposed IT2-FLC by using five simulation tasks including the model parameters changes, the disturbance in blood pressure which related to the use of stimuli such as the Surgeon's knife when cutting tissue which tents to make the blood pressure rise to undesired values, and the applying an environmental noise that affect the system. All simulation results for proposed IT2-FLC were compared with T1-FLC as another technique. Results show that the proposed IT2-FLC is able to respond to the uncertainty that introduced by large inter-individual and intra-individual variability of the patient's parameters. Also, it is able to reduce the effect of disturbance and noise environment. Results also show the IT2-FLC affords some improvements in performance over T1FLC.

\section{REFERENCES}

[1] Mahfouf M., Asbury A. J. and Linkens D. A., "Physiological Modeling and Fuzzy Control of Anaesthesia via Vaporization of Isoflurane by Liquid Infusion", I.J. of Simulation, Vol. 2, No. 1, PP. 55-66, 2000

[2] Gentilini A., Frei C.W., Glattfedler A.H., Morari M., Sieber T.J., Wymann R., Shnider T. W. and Zbinden A.M., "Multitasked Closed-loop Control in Anesthesia", Engineering in Medicine and Biology Magazine, IEEE, Vol. 20, PP. 39-53, 2001.

[3] Mahfouf M. and Linkens A. D., "Generalized Predictive Control and Bioengineering", T. J. International Ltd, Padstow, UK, 1998.

[4] Derighetti M., "Feedback Control in Anaesthesia", Ph.D Thesis, Swiss Federal Institute of Technology (ETH), Zurich, Switzerland, 1999.

[5] Shieh S. J., Linkens A. D. and Peacock E. J., "Hierarchical Rule-based and Self-organizing Fuzzy Logic Control for Depth of Anaesthesia", IEEE Transaction on Systems, Man, and Cybernetics-Part C, Vol. 29, No. 1, February 1999. 
[6] El- Rabaie N., Awad H. A. and Mahmoud T. A., "A noval Neural Networkbased Control Scheme for Controlling the Multivariable Anaesthesia", Minufiya Journal of Electronic Engineering Research (MJEER), Vol. 17, No. 1, 2007.

[7] Martin JF., "Fuzzy Control In Anesthesia", Journal of Clinical Monitoring, Vol. 10, No. 2, March 1994.

[8] Elkfafi M., Shieh J.S., Linkens D. A. and Peacock J. E., "Fuzzy logic for auditory evoked response monitoring and control for depth of anaesthesia", Fuzzy Sets And Systems, Vol. 100, PP. 29-43, 1998.

[9] Rahim F., Deshpande A. and Hosseini A., "Fuzzy expert system for fluid management in general anaesthesia", Journal Of Clinical And Diagnostic Research, Vol. 4, PP. 256-267, August 2007.

[10] Castillo O. and Melin P., "Type-2 Fuzzy Logic: Theory and Application", Studfuzz 223, PP. 29-43, 2008.

[11] Mendel J. M., John R. I. and Feilong Liu, "Interval Type-2 Fuzzy Logic Systems Made Simple", IEEE Trans. Fuzzy Syst., Vol. 14, No. 6, December 2006.

[12] Hagrs H. "Type-2 FLCs: A New Generation of Fuzzy Controllers", IEEE Computationl Intelligence Magazine, PP. 30-43, February 2007.

[13] Jammeh E. A., Fleury M., Wagner C., Hagres H. and Ghanbari M., "Interval Type-2 Fuzzy Logic Congestion Control for Video Streaming Across IP Networks", IEEE Trans. Fuzzy Syst., Vol. 17, No. 5, October 2009.

[14] Dongrui W. W. "A simplified Type-2 Fuzzy Logic Controller for Real-time Control", ISA Trans., Vol. 45, No. 4, PP. 503-516, October 2006.

[15] Liu Z., Zhng Y. and Wang Y., "A type-2 Fuzzy Switching Control System for Biped Robots", IEEE Transaction on Systems, Man, and CyberneticsPart C, Vol. 37, No. 6, November 2007.

[16] Shu H., Liang Q. and Gao J., "Wireless Sensor Network Lifetime Analysis Using Interval Type-2 Fuzzy Logic Systems", IEEE Trans. Fuzzy Syst., Vol. 16, No. 2, April 2008.

[17] Mendel J. M. and John R. I. "Type-2 Fuzzy Sets Made Simple", IEEE Trans. Fuzzy Syst., Vol. 10, No. 2, April 2002.

[18] Liang Q. and Mendel J. M., "Interval Type-2 Fuzzy Logic Systems: Theory and Design", IEEE Trans. Fuzzy Syst., Vol. 8, No. 5, April 2000.

[19] Karnik N. N., "Type-2 Fuzzy Logic Systems", Ph.D. Dissertation, University of Southern California, Los Angeles, CA 1998.

[20] Mendel J. M., "Type-2 Fuzzy Sets and Systems: An overview", IEEE Computational Intelligence Magazine, PP. 20-29, February 2007.

[21] Michel M. R. F., Eric P. M., Tom D. S., "Closed loops in anaesthesia", Best Practice \& Research Clinical Anaesthesiology, Vol. 20, No. 1 PP. 211-220, 2005.

[22] Chiristian W. F., Derighetti M., Morari M., Glattfeder A. H. and Zbinden A. M., "Improving Regulation of Mean Arterial Blood Pressure during Anesthesia through Estimates of surgery Effects", IEEE Trans. On Biomedical Engineering, Vol. 47, No.11, November 2000. 


\section{حاكم غيمى من النوع الثانى للتحكم فى نظام التخدير متعدد المتغيرات}

ان تطبيق نظم التحكم فى منظومة التخدير متعددة الدخول والخروج ينطلب اختبار الكثبر من المتغيرات

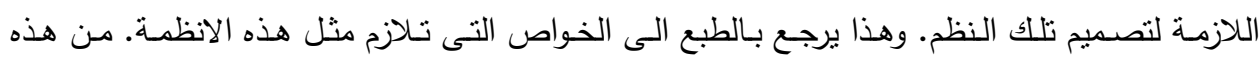

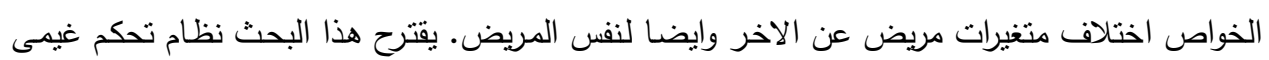

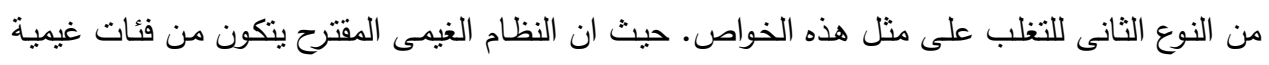

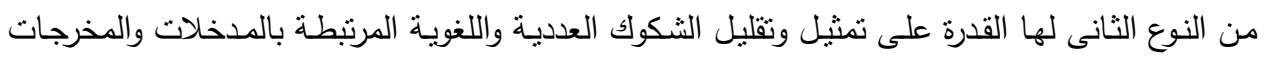

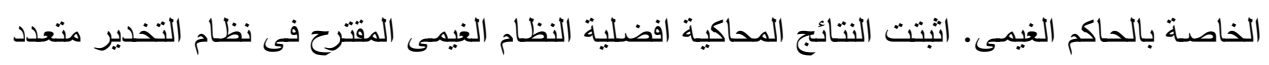

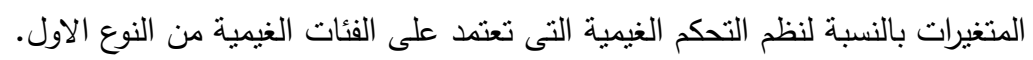

